\title{
Exploring sociality and engagement in play through game-control distribution
}

\author{
Marco C. Rozendaal - Bram A. L. Braat • \\ Stephan A. G. Wensveen
}

Received: 5 April 2009/Accepted: 20 November 2009/Published online: 20 December 2009

(C) The Author(s) 2009. This article is published with open access at Springerlink.com

\begin{abstract}
This study explores how distributing the controls of a video game among multiple players affects the sociality and engagement experienced in game play. A video game was developed in which the distribution of game controls among the players could be varied, thereby affecting the abilities of the individual players to control the game. An experiment was set up in which eight groups of three players were asked to play the video game while the distribution of the game controls was increased in three steps. After each playing session, the players' experiences of sociality and engagement were assessed using questionnaires. The results showed that distributing game control among the players increased the level of experienced sociality and reduced the level of experienced control. The game in which the controls were partly distributed led to the highest levels of experienced engagement, because the game allowed social play while still giving the players a sense of autonomy. The implications for interaction design are discussed.
\end{abstract}

Keywords Sociality · Engagement - Games · Play · Interaction design $\cdot$ Interdependence

M. C. Rozendaal $(\bowtie)$ · B. A. L. Braat · S. A. G. Wensveen

Designing Quality in Interaction,

Department of Industrial Design,

Eindhoven University of Technology,

Eindhoven, The Netherlands

e-mail: m.c.rozendaal@tue.nl

B. A. L. Braat

e-mail: b.a.l.braat@student.tue.nl

S. A. G. Wensveen

e-mail: s.a.g.wensveen@tue.nl

\section{Introduction}

While the focus on interactive system design has up to now been on optimizing user-system interaction at an individual level, a current trend is to optimize user-system interaction at a social level, involving small groups, crowds or society as a whole (Nishida 2007). Examples are the design of online (gaming) communities; collaborative environments and user-generated-content applications. These digital manifestations of sociality have been able to emerge because of the increased power of networking technologies and the availability of these technologies throughout society (Hallnäs and Redström 2002). A second trend in interactive system design is the shift from usability to emotionally laden aspects such as fun (Norman 2004; Wensveen et al. 2004), beauty (Overbeeke et al. 2002; Hassenzahl 2004) and engagement (Quesenbury 2002; Hornbæk 2006; Lindley 2004). Here, the focus is on pursuing positive qualities in interaction rather than avoiding negative ones, which traditionally has been the usability agenda (Hancock et al. 2005). Engagement is of interest in the current study. The aim of this study is therefore to investigate how experiences of sociality and engagement relate, and how they can be designed into interactive systems.

\subsection{Experienced engagement}

In the literature, engagement is described as an exciting and enjoyable state of mind in which attention is willingly given and held (Laurel 1991; Jacques et al. 1995; Webster and Ho 1997; Chapman et al. 1999) and has been researched in relation to video games, web applications and interactive training simulations (Malone 1981; Chen et al. 1999; Novak et al. 2000; Garris et al. 2002). An 
engagement framework has been developed to explicate the experience of engagement and the factors influencing it in order to support interactive system design (Rozendaal et al. 2009a, 2009b).

In brief, the engagement framework explains the levels of experienced engagement in terms of the levels of experienced richness and control (Fig. 1). Experienced engagement was found to be a multifaceted construct incorporating the experiences of enjoyment, development, challenge and autonomy. Engaging experiences can therefore be considered to be self-reinforcing. Experiences of richness and control were found to influence the levels of experienced engagement. Experienced richness captures the variety of thoughts, actions and perceptions (Fiske and Maddi 1961) that can be evoked by a user interface (Rozendaal et al. 2007a). Experienced richness creates engagement by providing a sense of excitement and challenge, thereby enticing people to interact. Experienced control captures the effort that is experienced in the selection and attainment of goals (Ajzen 2002). The more effort is experienced, the lower the levels of experienced control. Control creates engagement by providing a sense of autonomy during interaction; people feel able to interact freely.

The engagement framework is strongly associated with Vygotsky's 'Zone of Proximal Development' (ZPD) and Csikszentmihalyi's 'Flow theory'. In Vygotsky's learning theory (1978), the ZPD is regarded as an essential ingredient for effective learning. The ZPD is defined as the discrepancy between a learner's actual competency level and the level that can be attained when supported by a more capable peer (Luckin and du Boulay 1999). Learning is less effective when a learning activity relies too much on a student's current competencies, or when it lacks a clear support structure (Sanders and Welk 2005). Csikszentmihalyi describes the state of Flow (1990) as an optimal experience in which an individual feels fully

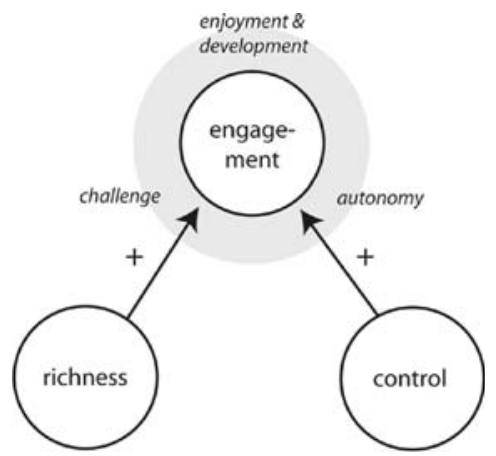

Fig. 1 Schematic overview of engagement. Based on the factor analytical results, engagement is conceptualized as a multifaceted construct involving enjoyment, development, challenge and autonomy influenced by experiences of richness and control absorbed in an activity. Flow is achieved when an activity demands both challenge and skill. Sub-optimal experiences arise when either of these requirements is lacking: a lack of challenge results in experienced boredom, while a lack of skill results in experienced anxiety. ZPD and Flow describe the conditions in which human potential is best developed and human experience is optimal. The engagement framework aims to set guidelines on how these conditions can be designed into interactive systems.

\subsection{Experienced sociality}

Experienced sociality in interaction can be investigated from different perspectives and on different scales. In the current study, experienced sociality is captured by group affiliation, social action and social roles. These are investigated on the scale of minimal groups-triads-that are considered to be the smallest possible social group (Stangor 2004). Experienced group affiliation entails the extent to which the individual feels a member of a social group (Spencer-Rodgers et al. 2007) and is promoted by perceived similarities in others' appearance and behavior (Campbell 1958). Due to the intrinsic enjoyment of communication and camaraderie, experienced group affiliation is considered to be a possible factor of engagement. Experienced social action relates to the extent to which the individual feels part of a shared activity and can involve simultaneous individual action, cooperation and/or competition (Johnson and Johnson 2005). While cooperative social action promotes the success of others, it is obstructed in competitive social action. In both situations, however, social action is possible when individuals within a group are aware of each other's goals and actions to help them to coordinate their own actions. Social action is considered relevant for engagement since engagement concerns the connection between a person and his/her (social) environment. Lastly, experiencing social roles involves the awareness of the relationship of the individual to others within a social group. In everyday conduct social roles are dynamic, since the external influences in which groups are formed change as well as individual motivations (Stangor 2004). Individuals therefore need to change roles sometimes to maintain an optimal social situation. Experienced social roles are of interest for engagement since the engagement may also be influenced by the social dynamics unfolding during interaction.

\subsection{System features affording engagement and sociality}

How can interactive systems that afford engagement and sociality best be designed? Previous studies showed that by increasing the vividness and interactivity of a user 
interface, the sense of engagement during interaction increased (Rozendaal et al. 2007b). Interactivity as defined by Steuer (1992) involves the extent to which an individual can influence system parameters and combines both the possibilities of the system and the human action that is needed to activate those possibilities. With increased interactivity, users are free to switch between goals and strategies (Manninen 2002), thereby allowing them to interact in an increasingly expressive and personal manner (Hummels and van der Helm 2004; Wensveen 2005). Vividness as defined by Steuer (1992) involves the representational richness of a medium and is increased by using rich imagery, audio feedback and/or haptic feedback within the user interface design. Vividness promotes engagement by providing multisensory stimulation during interaction.

Physical features of interactive systems can also influence the direction and intensity in which sociality unfolds during interaction. These physical features supporting social functionality are called social affordances. The term affordance, defined as the possibility for action, stems from ecological psychology (Gibson 1977) and has been discussed in relation to sociality by Hodges and Baron (2007). While affordances initially related to the physical features allowing perceptual-motor activities such as walking, throwing, sitting, social affordances relate to how physical features allow communication, cooperation and sharing. Social affordances have been discussed in relation to interactive systems (Gaver 1996) and in relation to computer cooperative learning environments (Volet and Wosnitza 2004; Kreijns et al. 2007). While in many of these interactive (social) systems, the focus is on the digital contents, Fruchter (2005) and Ludvigsen (2006) emphasize that a system's spatiality and physicality should be designed simultaneously with these digital contents in order to create effective social interaction in distributed workspaces and library environments, respectively.

\subsection{Game-control distribution}

The current study aims to explore how engagement and sociality are affected by distributing game control among multiple players. Game controls are physical devices used to manipulate the digital contents of video games. Examples are joysticks, keyboards and gestural input devices such as that of the Nintendo 'Wii'. In multiplayer games, players are able to manipulate avatars simultaneously within a virtual game environment. Other players can be virtually present-as with networked games-and/or physically present - as with colocated play. By distributing game control among players in such settings, individual players' actions affect other players' action possibilities thereby making game play more social. However, the question is to exactly what extent game-control distribution will affect experienced sociality, and how experienced sociality intertwines with experienced engagement.

\section{Method}

\subsection{Prototype}

A video game was created to investigate how distributing game control among multiple players affects sociality and engagement in game play. The video game, resembling the classic arcade game 'Asteroids', was played on a gaming platform consisting of a large wall-mounted display and three game consoles (Fig. 2). The game involved three spaceships moving through a two-dimensional space while asteroids entered the playing field from all sides (Fig. 3). Points could be earned by shooting down asteroids and lost when asteroids hit the spaceships. Both the spaceships and asteroids could vary in color, and asteroids could only be shot by spaceships of a matching color.

The virtual spaceship avatars could be manipulated via game consoles. Each game console incorporated a joystick, rotation dial and a slider (Fig. 4). While the joystick was handheld, the component integrating the rotation dial and slider was fixed to the table. The joystick was used to move a spaceship across the two-dimensional playing field, and the spaceship's bullets were fired by pressing down on the joystick. Additionally, the rotation dial controlled the direction in which the bullets could be fired. The slider controlled the color of the spaceship. By moving the slider from left to right, a choice of eight spaceship colors could
Fig. 2 Picture of the gaming system in the living room environment of the '/d.searchlab' in the Industrial Design department. Left: players using the physical game controls. Right: game presentation on a flat panel television
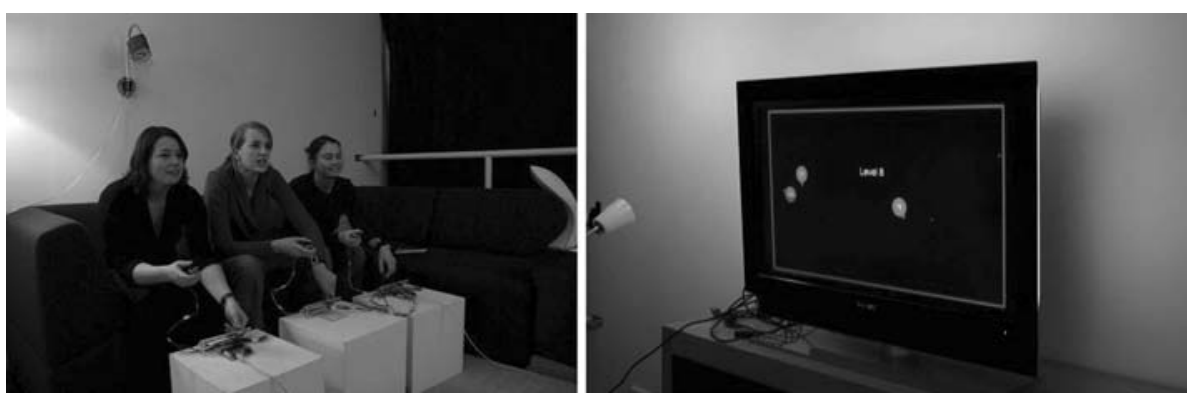


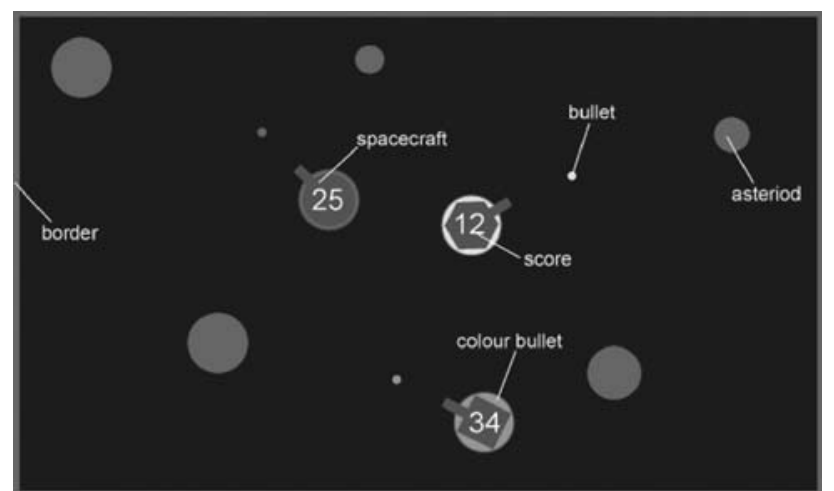

Fig. 3 Impression of the virtual game world

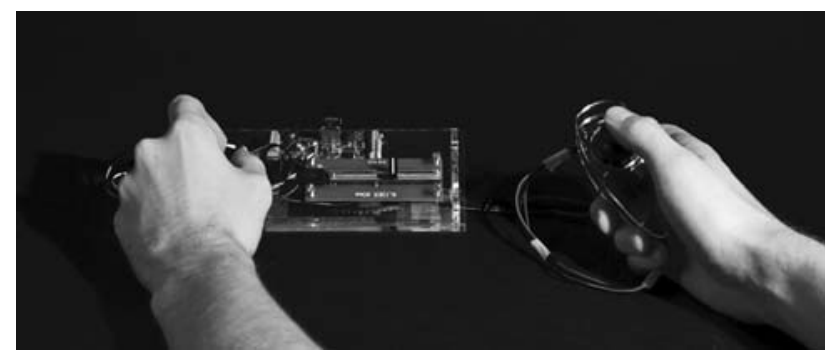

Fig. 4 Overview of the game console

be selected in the following order: red, orange, yellow, green, blue, purple, black and white. These colors were indicated above the slider at the corresponding slider locations. Points could be earned in the game by shooting the asteroids and lost when an asteroid collided with a spaceship. One point was added for each asteroid that was destroyed, and ten points were subtracted each time a spaceship was hit by an asteroid. Each aircraft started with 50 points, and points could be added or subtracted during the game. Individual scores were displayed on the spaceship avatars (Fig. 3). Although scores could be reduced to negative values, this did not affect the game structurally.

The controls of the game could be partly or fully distributed among the players, or not at all (Table 1). When the game controls were not distributed among the players, the game was configured as described earlier. When the game controls were partly distributed, the mapping of the slider in relation to the spaceship color changed. Slider control was then distributed among players in such a way that the color setting was based on each player's individual setting of red, yellow, blue or off for all three spaceships simultaneously by using the game-control slider. Players therefore needed to coordinate slider action to create one of the eight colors together. When the game controls were fully distributed among the players, the game involved one shared spaceship avatar, with one of the players controlling its movement via the joystick, a second player controlling
Table 1 Overview of the game-control distribution levels

\begin{tabular}{|c|c|c|c|c|}
\hline $\begin{array}{l}\text { Level of game-control } \\
\text { distribution }\end{array}$ & $\begin{array}{l}\text { Game } \\
\text { function }\end{array}$ & Player A & Player B & Player C \\
\hline \multirow[t]{4}{*}{ None } & Movement & $\bullet$ & $\bullet$ & $\bullet$ \\
\hline & Rotation & $\bullet$ & $\bullet$ & $\bullet$ \\
\hline & Shooting & $\bullet$ & $\bullet$ & $\bullet$ \\
\hline & Color & All & All & All \\
\hline \multirow[t]{4}{*}{ Partly } & Movement & $\bullet$ & $\bullet$ & $\bullet$ \\
\hline & Rotation & $\bullet$ & $\bullet$ & $\bullet$ \\
\hline & Shooting & $\bullet$ & $\bullet$ & $\bullet$ \\
\hline & Color & Yellow & Red & Blue \\
\hline \multirow[t]{4}{*}{ Full } & Movement & $\bullet$ & & \\
\hline & Rotation & & $\bullet$ & \\
\hline & Shooting & & & $\bullet$ \\
\hline & Color & Yellow & Red & Blue \\
\hline
\end{tabular}

its rotation by the rotation dial, and a third player controlling its shooting ability through the joystick button.

\subsection{Experimental design}

An experiment was set up in which game-control distribution could be varied in three incremental steps as described earlier. In each run of the experiment, groups of three participants experienced all of the possible conditions. This was repeated eight times. In each experimental condition, games could be played for a maximum of $3 \mathrm{~min}$. This maximum was based on the results of an earlier pilot study in which an estimate was made of the point at which the majority of players would experience boredom. Lastly, the experimental conditions were presented in a randomized order to prevent expertise effects.

\subsection{Participants}

In total, 24 subjects participated in the experiment divided into eight groups of three people. Of the participants, 17 were men and 7 were women. All of the participants were students in the Industrial Design department aged between 22 and 27, and all participants were native Dutch speakers.

\subsection{Procedure and measures}

The experiment was carried out in the living room environment of the '/d.search-lab' of the Industrial Design department. Participants were asked to sit side-by-side on a couch. In front of them were tables on which the game consoles were placed. Facing the players was a wallmounted flat panel television. Participants were told that the aim of the study was to assess social aspects of gaming without giving any further explanation. After each 
Table 2 List of items assessing sociality alphabetical order

Adequate group reaction
Blocked by others
Collectiveness
Communication
Cooperation
Feeling ignored

Feeling isolated

Group effectiveness

Influencing others

Positive group atmosphere

Potential to conform

Potential to lead
Proud of group action

Social connectedness

Solidarity

Team feeling

We feeling

Table 3 Items assessing the engagement construct

\begin{tabular}{llllll}
\hline Engagement factor & & & & Richness factor & Control factor \\
\hline$(1)$ & $(2)$ & $(3)$ & $(4)$ & $(5)$ & Clarity \\
\hline Engagement & New possibilities & Challenge & Freedom & Complexity & Control \\
Enjoyment & Skill development & Excitement & Personal style & Possibilities & Ease \\
Fun & & & Richness & Self-confidence \\
Motivation & & & Variety & \\
\hline
\end{tabular}

Items are grouped a priori according to previous results

experimental condition, the participants were asked to rate a total of 37 items - in which the sociality and engagement items were mixed randomly — on a ten-point scale using a pencil and paper. To assess sociality, items were included relating to group affiliation, social action and social roles. These items are listed alphabetically in Table 2. To assess engagement, items were chosen related to (1) enjoyment, (2) development, (3) challenge, (4) autonomy, (5) richness and (6) control. In Table 3, these items are grouped a priori according to previously obtained factor analytical results (Rozendaal et al. 2009a, 2009b). Further, two additional items are included in the engagement questionnaire. These items are labeled 'personal fit' and 'hindered'.

\section{Results and discussion}

\subsection{Experienced engagement and sociality}

To reduce the amount of data, a factor analysis was applied to the questionnaire results. A factor solution of six factors resulted in the most intuitive result that explained about $63 \%$ of the total variance (Table 4). For each factor, Cronbach's alpha was calculated to assess the internal consistency of the items included in a factor. The critical alpha value of .700 was used to decide whether to include or exclude an item: an alpha value above .700 indicates that a selection of items measures a single construct and that those items can be grouped in further analysis (Carmines and Zeller 1979). Factor I-labeled sociality-captures most of the sociality items. The internal consistency of the items is high $(.928,13$ items). Factor II-labeled engagement-combines the enjoyment, development and autonomy items. Internal consistency is also high for this collection of items (.869, 11 items). However, the 'personal style', 'freedom' and 'challenge' items have lower factor loadings on this factor compared to the previously obtained factor analytical results. Factor III-labeled controlincludes two of the autonomy items 'personal style' and 'freedom' and 'blocked by others' (inversed). The internal consistency of these items was acceptable (.727, 4 items), but deleting the 'blocked by others' item greatly increased it (.824, 3 items). Factor IV-labeled richness-includes the 'variety', 'challenge' and 'positive group atmosphere (inversed)' items. The internal consistency for this selection of items is low $(.630,4$ items). By deleting the 'positive group atmosphere' item, the internal consistency is increased to an acceptable level (.730, 3 items). Factor $\mathrm{V}$-labeled efficacy-includes the items that were part of the control factor obtained in the earlier study referred to earlier, but the internal consistency for this selection of items turns out to be very low (.382, 3 items). Factor VIlabeled conflict-also had a low internal consistency (.609, 2 items). In view of these scores, both sets of items were not taken into account for further statistical analysis.

The current factor analytical results were similar to the factor analytical results found in earlier studies. However, some differences in the items' factor loadings were found. For experienced engagement, the items assessing 'freedom' and 'personal style' had higher factor loadings on the control factor and lower factor loadings on the engagement factor. This result emphasizes a stronger association of experienced control and experienced autonomy. Control may therefore be considered to assess decisional control, defined by Averill (1973) as the “...range of choice or number of options open to an individual" (p. 298). The items included in the efficacy factor-which were considered as part of the control factor-may have captured other 
Table 4 Table showing the 6-factor solution, presented with varimax rotation

\begin{tabular}{|c|c|c|c|c|c|c|}
\hline & $\begin{array}{l}\text { I } \\
\text { Sociality }\end{array}$ & $\begin{array}{l}\text { II } \\
\text { Engagement }\end{array}$ & $\begin{array}{l}\text { III } \\
\text { Control }\end{array}$ & $\begin{array}{l}\text { IV } \\
\text { Richness }\end{array}$ & $\begin{array}{l}\mathrm{V} \\
\text { Efficacy }\end{array}$ & $\begin{array}{l}\text { VI } \\
\text { Conflict }\end{array}$ \\
\hline Social connectedness & .913 & & & & & \\
\hline Team feeling & .899 & & & & & \\
\hline Cooperation & .891 & & & & & \\
\hline We feeling & .870 & & & & & \\
\hline Collectiveness & .824 & & & & & \\
\hline Communication & .738 & & & & & \\
\hline Group effectiveness & .694 & & & & .326 & \\
\hline Influencing others & .665 & & & & & \\
\hline Solidarity & .638 & & & & & \\
\hline Pride in group accomplishment & .630 & & & & & \\
\hline Isolation & -.626 & & & & & \\
\hline Potential to conform & .575 & & -.309 & & & \\
\hline Potential to lead & .443 & & .426 & & & \\
\hline Fun & & .867 & & & & \\
\hline Enjoyment & & .820 & & & & \\
\hline Excitement & & .810 & & & & \\
\hline Complexity & & .694 & & & -.450 & \\
\hline Possibilities & & .656 & & & & \\
\hline New possibilities & & .633 & -.411 & & & \\
\hline Skill development & & .569 & & & & \\
\hline Personal fit & & .567 & & & .509 & \\
\hline Motivation & & .551 & & & & .506 \\
\hline Engagement & .458 & .537 & & & & \\
\hline Hindered & & -.430 & -.379 & -.361 & -.361 & \\
\hline Control & & & .804 & & & \\
\hline Personal style & -.410 & .417 & .639 & & & \\
\hline Freedom & & .317 & .563 & .328 & & \\
\hline Blocked by others & & & -.378 & .321 & -.301 & .348 \\
\hline Richness & & & & .801 & & \\
\hline Variety & & & & .732 & & .339 \\
\hline Challenge & & .334 & & .523 & -.444 & \\
\hline Positive group atmosphere & .340 & & .395 & -.401 & & \\
\hline Self-confidence & & & & & .627 & \\
\hline Ease & .442 & & & & .546 & \\
\hline Clarity & & & & & .465 & \\
\hline Ignored by others & & & & .307 & & .757 \\
\hline Adequate group reaction & & & & & & -.700 \\
\hline Eigenvalue & 8.664 & 6.037 & 2.998 & 2.068 & 1.807 & 1.601 \\
\hline Variance explained (\%) & 23.416 & 16.317 & 8.103 & 5.590 & 4.883 & 4.328 \\
\hline
\end{tabular}

Extraction method: Principal component analysis. Rotation method: Varimax with Kaiser normalization $N=72$ (24 participants $\times 3$ levels of game-control distribution) Factor loadings $<.3$ are omitted

types of control, such as Averill's behavioral or cognitive control dimensions. Contrary to previous findings, the item assessing 'challenge' had a higher factor loading on the richness factor and lower factor loading on the engagement factor, while the items assessing 'complexity' and 'possibilities' had higher factor loadings on the engagement factor and lower factor loadings on the richness factor. This shift could illustrate that experienced richness is based more on the social interactions afforded by game features and less on the game features themselves. 
However, this remains speculative. Results further showed that experienced sociality, engagement and control were associated. The item assessing 'engagement' had a factor loading higher than .300 on the engagement factor as well as the sociality factor, illustrating a form of engagement possibly involving empathy. The items assessing 'potential to conform', 'potential to lead' and 'personal style' had factor loadings higher than .300 on both the control and sociality factors: Adopting a conforming role may lead to decreased feelings of control, while feelings of control may increase when adopting a leading role. Lastly, feeling connected to others may decrease a sense of 'personal style' when the individual feels the need to adjust to group norms.

\subsection{Game-control distribution effects}

To assess the effect of game-control distribution on the experiential variables, a Repeated Measures Multivariate Analysis was performed on the mean scores of the grouped items. The results show that game-control distribution significantly affected levels of experienced sociality, control and engagement, but did not significantly affect levels of experienced richness (Table 5). Distributing game control among the players led to increased levels of experienced sociality and decreased levels of experienced control (Fig. 5). As player action increasingly affected the action possibilities of other players, experienced sociality increased since players needed to coordinate their actions, often requiring verbal communication. Conversely, experienced control decreased since distributing game control across players decreased the number of parameters that individual players could manipulate using their game consoles. The levels of experienced engagement followed a slightly inversed U-shape curve with increasing levels of game-control distribution (Fig. 6). Partly, distributing game control among the players led to the highest level of experienced engagement since the players could pursue both individual and shared goals simultaneously, allowing social game play in which the players could maintain a sense of autonomy. Game-control distribution did not appear to affect the levels of experienced richness. Earlier studies showed that experienced richness is affected by the number of game functions (Rozendaal et al. 2007a, 2009a),

Table 5 Effects of game-control distribution on sociality, control, engagement and richness

\begin{tabular}{lll}
\hline Sociality & $F(2,46)=58,099$ & $p<.000^{*}$ \\
Control & $F(2,46)=19,590$ & $p<.000^{*}$ \\
Engagement & $F(2,46)=6,416$ & $p<.003^{*}$ \\
Richness & $F(2,46)=1,260$ & $p<.293$ \\
\hline
\end{tabular}

$* p<.005$

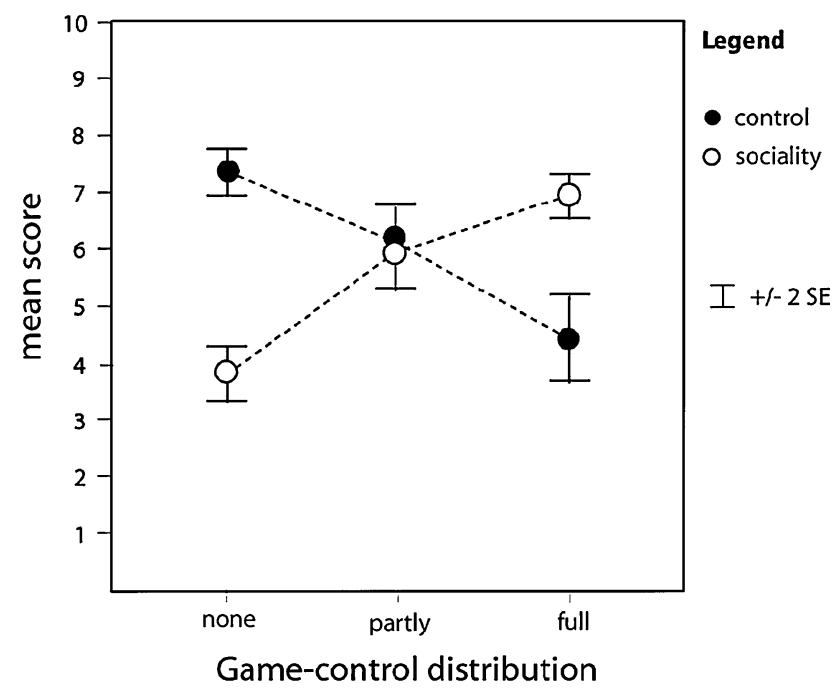

Fig. 5 Figure showing sociality and control as a function of gamecontrol distribution

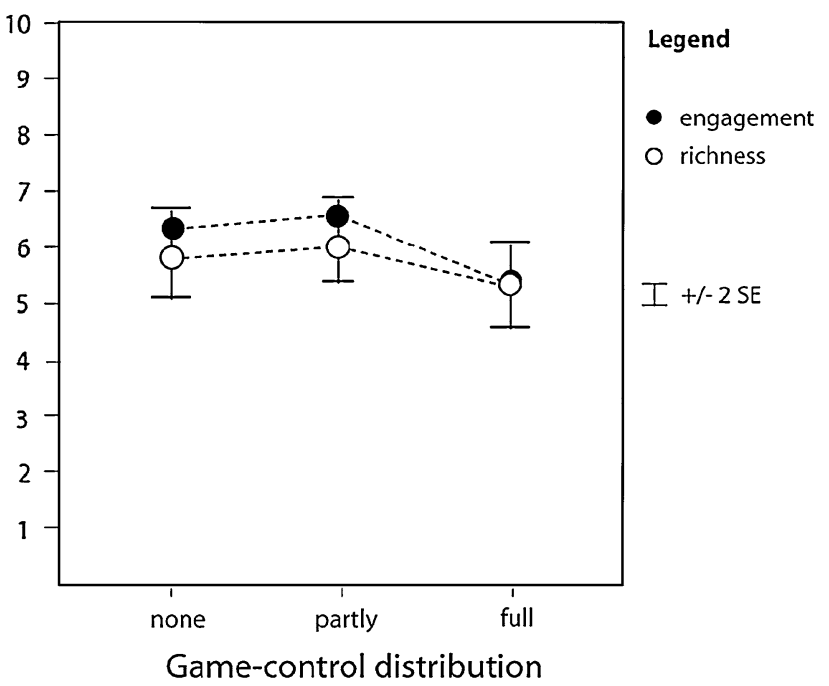

Fig. 6 Figure showing engagement and richness as a function of game-control distribution

and-based on the current results—not by the extent to which they are distributed among the players.

\section{Conclusion}

The results show that the experiences of sociality and engagement are intertwined and that they are influenced by game-control distribution and the social roles adopted by the players in game play (Fig. 7). Similar to the previous results referred to earlier in this paper, experienced engagement captures the extent to which interaction is selfreinforcing. However, some differences were observed. The shift of two autonomy items from the engagement 


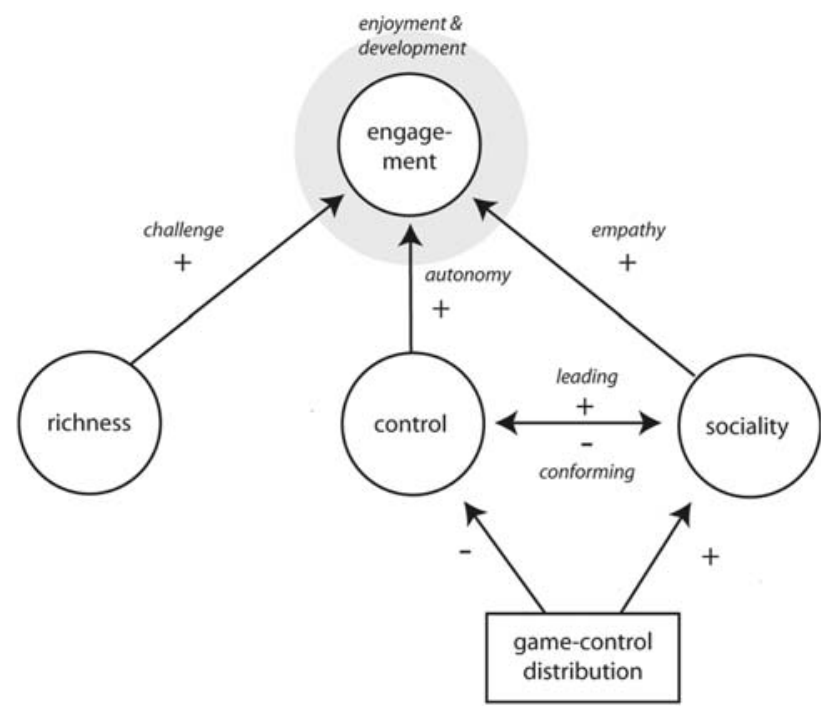

Fig. 7 Schematic overview of the relationships found for gamecontrol distribution on the sociality and engagement factors

factor toward the control factor, combined with the agglomeration of three of the a priori control items into a separate factor, led to the conclusion that various types of control defined by Averill (1973)—decisional, behavioral and cognitive control-should be made more explicit within the framework.

Experienced sociality was found to intertwine with experienced engagement in a number of ways. A direct relationship between sociality and engagement, possibly through empathy, was established. Indirect relationships between sociality and engagement were found through experienced control and experienced autonomy. The results showed that the experience of having a leading role or a conforming role within a social group correlated with experienced control. Further, the results revealed an inherent tension between experiencing a personal style in interaction and experiencing social connectedness: to experience social connectedness the individual needs to adapt to shared norms, possibly decreasing the sense of autonomy as a result.

Increasing game-control distribution among players increased the levels of experienced sociality in game play: the players felt increasingly connected with each other because of the increased opportunities for social action and communication. However, with increased levels of gamecontrol distribution the levels of experienced control decreased. By distributing game control among the players, fewer parameters could be influenced individually, which meant that players were subjected to the will of other players. Interestingly, the lack of experienced control at a manual level could be regained at a social level by adopting a leading role. Intermediate levels of game-control distribution led to the highest levels of engagement, since the game features allowed players to pursue personal goals and shared goals concurrently, and different social roles could be explored. As a critical note, since this study did not focus on individual differences, interaction effects between individual factors and physical features on experienced sociality and engagement remain unexplained. Future studies could assess socially significant personality traits before interaction takes place, as well as focusing more closely on the social dynamics unfolding during interaction.

How to design interactive systems that optimally engage users during interaction? First, creating sensorially and behaviorally rich systems promotes engagement at a physical level by extending the range of media used within the user interface and the range of action possibilities afforded by the system's interactivity. Engagement is promoted at a social level by designing multiple and varied pathways for shared access of system functionalities and by giving users some control of each other's action possibilities. Social awareness needs to be created by visualizing relevant social information such as identity, emotion and behavior that is needed to create empathy and effective social action. Work by Reeves et al. (2008) on leadership in online multiplayer game environments led to similar principles. For instance, game environments allowing safe and playful settings in which social roles can be explored result in highly dynamic working groups. These virtual environments should allow 'hypertransparency' of information about individual and group performance and should apply non-monetary incentives based on a game-world's intrinsic fantasy such as points, objects or spells. Applying these principles in physical work environments were found to enhance leadership effectiveness and may-as the authors state-even reshape the workplace itself.

To conclude, this study explored how distributing game control among players affected the levels of experienced sociality and engagement in game play. Including a social dimension within the engagement framework deepened the understanding of the engagement, richness and control constructs. The framework may guide the design of interactive systems but requires further study on social dynamics for it to be used as a prediction tool. Such tools are highly valued in interaction design since they can help in opening-up the digital domain for deeper social interactions, ultimately serving society as a whole.

Acknowledgments The authors would like to thank members of the '/d.search-lab' and Master's students of Industrial Design for having made this study possible.

Open Access This article is distributed under the terms of the Creative Commons Attribution Noncommercial License which permits any noncommercial use, distribution, and reproduction in any medium, provided the original author(s) and source are credited. 


\section{References}

Ajzen I (2002) Perceived behavioral control, self-efficacy, locus of control, and the theory of planned behavior. J Appl Soc Psychol 32(4):665-683

Averill JR (1973) Personal control over aversive stimuli and its relationship to stress. Psychol Bull 80(4):286-303

Campbell DT (1958) Common fate, similarity and other indices of the status of aggregates of persons as social entities. Behav Sci $3(1): 14-25$

Carmines EG, Zeller RA (1979) Reliability and validity assessment. Sage, Newbury Park

Chapman P, Selvarajah S, Webster J (1999) Engagement in multimedia training systems. HICSS-32 proceedings of the thirtysecond annual Hawaii international conference on system sciences, CD-ROM. IEEE, Maui

Chen H, Wigand RT, Nilan MS (1999) Optimal experience of web activities. Comput Hum Behav 15(5):585-608

Csikszentmihalyi M (1990) Flow: the psychology of the optimal experience. HarperCollins, New York

Fiske DW, Maddi SR (1961) A conceptual framework. In: Fiske DW, Maddi SR (eds) Functions of varied experience. The Dorsey press, Homewood, pp 11-56

Fruchter R (2005) Degrees of engagement in interactive workspaces. AI \& Society 19(1):8-21

Garris R, Ahlers R, Driskell JE (2002) Games, motivation, and learning: a research and practice model. Simulation \& Gaming 33(4):441-467

Gaver W (1996) Affordances for interaction: the social is the material for design. Ecol Psychol 8(2):111-129

Gibson JJ (1977) The theory of affordances. In: Shaw R, Bransford J (eds) Perceiving, acting, and knowing: toward an ecological psychology. Lawrence Erlbaum, Hillsdale, NJ, pp 67-82

Hallnäs L, Redström J (2002) From use to presence: on the expressions and aesthetics of everyday computational things. ACM Trans Comput-Human Interact 9(2):106-124

Hancock PA, Pepe AA, Murphy LL (2005) Hedonomics: the power of positive and pleasurable ergonomics. Ergonomics in design: The quarterly of human factors applications 13(1):8-14

Hassenzahl M (2004) The interplay of beauty, goodness, and usability in interactive products. Human-Comput Interact 19(4):319-349

Hodges BH, Baron RM (2007) On making social psychology more ecological and ecological psychology more social. Ecol Psychol 19(2):79-84

Hornbæk K (2006) Current practice in measuring usability: challenges to usability studies and research. Int J Human-Comput Stud 64(2):79-102

Hummels CCM, van der Helm A (2004) ISH and the search for resonant tangible interaction. Pers Ubiquit Comput 8(5):385-388

Jacques R, Preece J, Carey T (1995) Engagement as a design concept for multimedia. Canad J Educ Commun 24(1):49-59

Johnson DW, Johnson RT (2005) New Developments in social interdependence theory. Genet Soc Gen Psychol Monogr 131(4):285-358

Kreijns K, Kirschner PA, Jochems W, van Buuren H (2007) Measuring perceived sociability of computer-supported collaborative learning environments. Comput Educ 49(2):176-192

Laurel B (1991) Computers as theatre. Addison-Wesley, Reading

Lindley CA (2004) Ludic engagement and immersion as a generic paradigm for human-computer interaction design. In: Proc. ICEC2004. Springer, pp 3-13

Luckin R, du Boulay B (1999) Ecolab: the development and evaluation of a Vygotskian design framework. Int $\mathbf{J}$ Artif Intell Educ 10:198-220
Ludvigsen M (2006) Designing for social interaction-co-located, physical social computing. Doctoral dissertation, Department of Design, Aarhus School of Architecture

Malone TW (1981) Toward a theory of intrinsically motivating instruction. Cognit Sci 4:333-369

Manninen T (2002) Contextual virtual interaction as part of ubiquitous game design and development. Pers Ubiquit Comput 6(6):390-406

Nishida T (2007) Social intelligence design and human computing. Artificial intelligence for human computing. LNAI 4451:190 214

Norman DA (2004) Emotional design: why we love or hate everyday things. Basic Books, New York

Novak TP, Hoffman DL, Yung YF (2000) Measuring the customer experience in on-line environments: a structural modeling approach. Mark Sci 19(1):22-42

Overbeeke CJ, Djajadiningrat JP, Hummels CCM, Wensveen SAG (2002) Beauty in usability: forget about ease of use!. In: Green WS, Jordan PW (eds) Pleasure with products: beyond usability. Taylor and Francis, London, pp 9-18

Quesenbury W (2002) The five dimensions of usability. In: Albers M, Mazur B (eds) Content and complexity: information design in technical communication. Erlbaum, Mahwah, NJ, pp 81-102

Reeves B, Malone TW, O’Driscoll T (2008) Leadership's online labs. Harv Bus Rev 5:58-66

Rozendaal MC, Keyson DV, de Ridder H (2007a) Interactivity, vividness and richness in user interfaces. In: International workshop on social intelligence design (SID07). Trento, Italy, pp 269-278

Rozendaal MC, Keyson DV, de Ridder H (2007b) Product behavior and appearance effects on experienced engagement during experiential and goal-directed tasks. In: International conference on designing pleasurable products and interfaces (DPPI07). Helsinki, Finland, pp 181-194

Rozendaal MC, Keyson DV, de Ridder H, Craig PO (2009a) Game feature and expertise effects on experienced richness, control and engagement in game play. AI Soc 24(2):123-133

Rozendaal MC, Keyson DV, de Ridder H (2009b) Product features and task effects on experienced richness, control and engagement in voicemail browsing. Pers Ubiquit Comput 13(5):343354

Sanders D, Welk DS (2005) Strategies to scaffold student learning: applying Vygotsky's zone of proximal development. Nurse Educator 30(5):203-207

Spencer-Rodgers J, Hamilton DL, Sherman SJ (2007) The central role of entitativity in stereotypes of social categories and task groups. J Pers Soc Psychol 92(3):369-388

Stangor C (2004) Social groups in action and interaction. Psychology Press, New York

Steuer J (1992) Defining virtual reality: dimensions determining telepresence. J Commun 42(2):73-93

Volet S, Wosnitza M (2004) Social affordances and students' engagement in cross-national online learning: an exploratory study. J Res Int Educ 3(1):5-30

Vygotsky LS (1978) Mind and society: the development of higher psychological processes. Harvard University Press, Cambridge, MA

Webster J, Ho H (1997) Audience engagement in multimedia presentations. DATA BASE Adv Inf Syst 28(2):63-77

Wensveen SAG (2005) A Tangibility approach to affective interaction. Doctoral dissertation, Delft University of Technology, Delft, The Netherlands

Wensveen SAG, Overbeeke CJ, Djajadiningrat JP (2004) Freedom of fun, freedom of interaction. Interactions 11(5):59-60 